\title{
Microstructure and mechanical properties of Mg-HAP composites
}

\author{
ASIT KUMAR KHANRA*, HWA CHUL JUNG ${ }^{\dagger}$, SEUNG HOON YU ${ }^{\dagger}$, KUG SUN HONG ${ }^{\dagger}$ \\ and KWANG SEON SHIN ${ }^{\dagger}$ \\ Department of Metallurgical and Materials Engineering, National Institute of Technology, Warangal 605004 , India \\ ${ }^{\dagger}$ Magnesium Technology Innovation Centre, RIAM, School of Materials Science and Engineering, \\ Seoul National University, South Korea
}

MS received 25 April 2009; revised 8 July 2009

\begin{abstract}
In the present study, it has been attempted to develop biodegradable Mg-HAP (magnesiumhydroxyapatite) composite materials for bone replacement. At first the HAP powders were prepared by chemical synthesis process and synthesized powders were characterized by X-ray diffraction (XRD) and scanning electron microscope (SEM). Synthesized powders contain HAP as a major phase with tricalcium phosphate $(\beta$-TCP) as a minor phase. The Mg-HAP composites were prepared by adding different amounts of HAP powders to $\mathrm{Mg}$ melts and finally the billets were extruded. The microstructure of Mg-HAP composite was examined by optical microscope (OM). The presence of $\mathrm{HAP}$ in Mg matrix results in decrease of grain size of $\mathrm{Mg}$-HAP composites. The theoretical and experimental hardness of the composites are compared with the addition of HAP. The tensile strength of composites is found to decrease with the addition of HAP, whereas compressive strength increases with HAP.
\end{abstract}

Keywords. Mg; HAP; biodegradable; extrusion; hardness; compressive strength.

\section{Introduction}

The biodegradable nature of $\mathrm{Mg}$ makes it a most highlighted and interesting implant material of this century to the researcher. Many biomaterials have been developed over a few decades for the replacement of bone tissue. The metallic materials are found to be suitable biomaterials compared to the ceramic/polymeric due to combination of load bearing capacity and suitable mechanical and metallurgical properties. Generally, three types of metallic materials such as austenitic stainless steel (SS), $\mathrm{Co}-\mathrm{Cr}$ alloys and pure Ti and its alloys are being used for surgical implants (Kannan et al 2003; Staiger et al 2006). Till now SS is extensively used as most promising biomaterial for bone replacement. In vivo application of implant materials like plates, screw and pins require removal after healing of tissue by second surgical operation, which leads to unhealthfulness of the patient with extra surgical cost. It may be noted that the degradation of these metallic materials leads to toxic product, which results in loss of biocompatibility or loss of bone tissue. The property mismatch of natural bone and implant materials may lead to generation of stress and unstability of implants.

The physical and mechanical properties of natural bone are found to differ with those of conventional metallic implants but quite similar to $\mathrm{Mg}$. Magnesium is the fourth

*Author for correspondence (kkasit@yahoo.co.in) abundant cation in human body $(\sim 1 \mathrm{~mol} / \mathrm{adult})$ and mainly found in bone tissue and it stabilizes the DNA and RNA structures (Staiger et al 2006). Initially Mg based materials are first introduced as implant material due to its excellent biocompatibility but rapid corrosion rate of $\mathrm{Mg}$ alloys leads to application of more corrosion resistance materials like stainless steel, $\mathrm{Ti}$, etc. It is also found that different $\mathrm{Mg}$ alloys such as AZ91, AZ31, AZ31, WE43 and LAE442 show localized corrosion in in vitro and in vivo tests (Witte et al 2005, 2006, 2007a, b; Kaya 2007). It is reported that many researchers are also trying to use biodegradable $\mathrm{Mg}$ as coronary stents material and its performance is quite optimistic as compared to the permanent stent materials such as SS, Ta, Ti, NiTi, Co-Cr, Pt-Ir, etc (Erbel et al 2007; Mani et al 2007; Ormiston and Webster 2007).

Much attention has already been paid to calcium based biomaterials like HAP $\left(\mathrm{Ca}_{10}\left(\mathrm{PO}_{4}\right)_{6}(\mathrm{OH})_{2}\right), \quad \beta$-TCP $\left(\mathrm{Ca}_{3}\left(\mathrm{PO}_{4}\right)_{2}\right)$ for bone graft substitute due to their excellent biocompatibility, bioactivity and osteoconductive properties (Ryu et al 2002; Kwon et al 2003; Suchanek et al 2004a, b; Chakraborty et al 2007; Kannan et al 2007). The calcium phosphate group is the largest inorganic material of bone tissue and extensively used in orthopedic and dental applications (Paramanik et al 2007). The HAP has unique feature of biocompatibility than other phosphate groups. The HAP particles show very low solubility as compared to $\beta$-TCP in our body fluid (Kwon et al 2003). The HAP powders appear to be a suitable reinforc- 
ing material for the development of metal matrix composite materials like Ti-HAP, Ti-6Al-4V-HAP, AZ91-HAP etc for implant materials to control the corrosion rate (Ning and Zhou 2002; Thian et al 2002; Witte et al 2007c). The production of biodegradable AZ91-HAP composites by powder extrusion technique route (Witte et al 2007c) is reported. The use of both powders may lead to extra production cost as compared to other techniques. However, AZ91 alloy contains 8.5-9.7 wt.\% Al, which has detrimental effect on human beings especially when used as biodegradable implants for bone replacement. It is essential to develop a biocompatible composite material without adding any detrimental elements to humans.

Till now there is no study on the production of Mg-HAP composite, which may be an eco-friendly and non-toxic biodegradable implant for human. Present study attempts to produce $\mathrm{Mg}-\mathrm{HAP}$ composites by a cheap process such as casting route. Initially the chemical synthesis route is used for the production of HAP powders and then the Mg-HAP composites are prepared by a combination of melting and extrusion routes. The microstructure and mechanical properties of different $\mathrm{Mg}-\mathrm{HAP}$ composites are evaluated.

\section{Experimental}

In the chemical synthesis of HAP powders, the laboratory reagent grade $\mathrm{Ca}(\mathrm{OH})_{2}(99 \%$ purity, High Purity Co., Ltd., Japan) and $\mathrm{H}_{3} \mathrm{PO}_{4}$ (85\% purity, Junsei Chemicals Co., Ltd., Korea) powders were used as precursor for $\mathrm{Ca}$ and $\mathrm{P}$, respectively. Initially, $33.52 \mathrm{~g}$ of $\mathrm{Ca}(\mathrm{OH})_{2}$ and $30.98 \mathrm{~g}$ of $\mathrm{H}_{3} \mathrm{PO}_{4}$ powders were dissolved in $450 \mathrm{ml}$ of distilled water separately to maintain stoichiometric HAP $(\mathrm{Ca} / \mathrm{P}: 1 \cdot 67)$. Then both solutions were mixed in a beaker and ultrasonically stirred for $3 \mathrm{~h}$. The white slurry was filtered and dried at $90^{\circ} \mathrm{C}$. The dried cake was calcined at $1100^{\circ} \mathrm{C}$ for $4 \mathrm{~h}$ and finally the calcined product was crushed. The detailed description of chemical synthesis of HAP powders is explained elsewhere (Kim and Saito 2001; Prakash et al 2006). HAP powders were characterized by X-ray diffraction (XRD) (M18XHF-22-SRA, Mac Science Co., Ltd., Japan) with $\mathrm{Ni}$ filtered $\mathrm{Cu}-\mathrm{K}_{\alpha}$ $(\lambda=1.54 \AA)$ radiation. The samples were scanned from $20-90^{\circ}$ of $2 \theta$ at a scan rate of $5 \% \mathrm{~min}$. The morphology of HAP powders was investigated by scanning electron microscope (SEM) (JEOL, JSM 630).

The $99.9 \%$ pure $\mathrm{Mg}$ ingot was melted in a stainless steel crucible under the protection of gas mixture containing $\mathrm{SF}_{6}$ and $\mathrm{CO}_{2}$. The different amounts of HAP powders $(0,5,10$ and $15 \mathrm{wt} . \%)$ were added slowly to the molten $\mathrm{Mg}$ at $700^{\circ} \mathrm{C}$ and a special stirring system was used to get better distribution of HAP particles in the $\mathrm{Mg}$ matrix. After melting, the ingots were subjected to homogenizing treatment at $400^{\circ} \mathrm{C}$ for $12 \mathrm{~h}$. The homogenized ingots were machined, which were used as raw materials for extrusion (Yoo Chang, Korea). The extrusion of billets was performed at $320^{\circ} \mathrm{C}$.

The extruded samples were cut into different pieces for the evaluation of various physical and mechanical properties. The density of different samples was measured by Archimedes principle with an error of $\pm 0 \cdot 01 \%$. The density was measured at $25^{\circ} \mathrm{C}$ using distilled water as medium. An average of 5 readings was taken for each reported density. The phase analysis of samples was performed by XRD, whereas, microstructural study of Mg-HAP composites were investigated by optical microscope (OM). The samples were prepared by polishing on $\mathrm{SiC}$ papers up to 2,000 grit and cloth polishing using $1 \mu \mathrm{m}$ diamond paste. The $5 \%$ nital solution was used as an etchant for Mg-HAP composites, whereas a mixture of acetic acid $(10 \mathrm{ml})$, picric acid $(4.2 \mathrm{~g})$, distilled water $(10 \mathrm{ml})$ and ethanol (70 $\mathrm{ml}$ of $95 \%$ purity) was used for the etching of pure $\mathrm{Mg}$ sample. The average grain size of $\mathrm{Mg}-\mathrm{HAP}$ composite was measured by the line intercept method and a minimum of 400 grains were counted. The Vickers hardness of the different samples was measured by Wolpert hardness tester. The reported hardness values of composites were the average of 15 readings. Cylindrical tensile and compressive specimens were machined along the extrusion direction of the rod, and tests were carried out at room temperature on an Instron testing machine with an initial strain rate of $2 \times 10^{-4} / \mathrm{s}$. The sample sizes were taken as per ASTM standard of E8 for tensile test and E9 for compressive test which describe the exact size.

\section{Results and discussion}

The calcined powders are found to be white in colour. The XRD pattern of calcined powder is shown in figure 1. The powder consists of HAP (JCPDS file: 74-0566) as a major phase with $\beta$-TCP (JCPDS file: 25-0378) (tricalcium phosphate) as a minor phase. The volume fraction

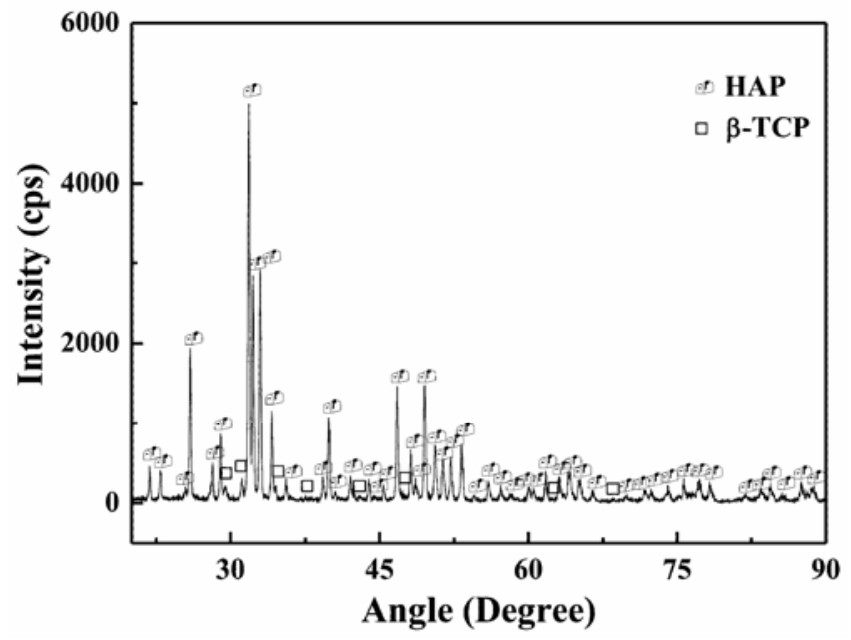

Figure 1. XRD pattern of HAP powder. 
of HAP and $\beta$-TCP is calculated from XRD pattern and the amount is found to be $\sim 94.46$ and $\sim 5.33$ vol.\% for HAP and $\beta$-TCP, respectively. It has been reported that the dissolution behaviour of HAP in human body is low, whereas $\beta$-TCP has high dissolution rate (Kwon et al 2003). The presence of biphasic apatite is useful to get the optimum restorability of the materials and the restorability of biphasic apatite is determined by the $\mathrm{HAP} / \beta$ TCP ratio. Here the presence of $\beta$-TCP as a minor phase in HAP powders is a bonus from the biocompatibility point of view. The SEM observation reveals the morphology of calcined powders (figure 2). The powder consists of agglomeration of fine particles $(1 \sim 5 \mu \mathrm{m})$ and the shape of the particles is mainly nonspherical and angular.

The density of the Mg-HAP composites is found to be 98 99\%. The XRD patterns of extruded samples are shown in figure 3 . The HAP and $\mathrm{MgO}$ are found as minor phases in case of $\mathrm{Mg}-\mathrm{HAP}$ composites. The presence of

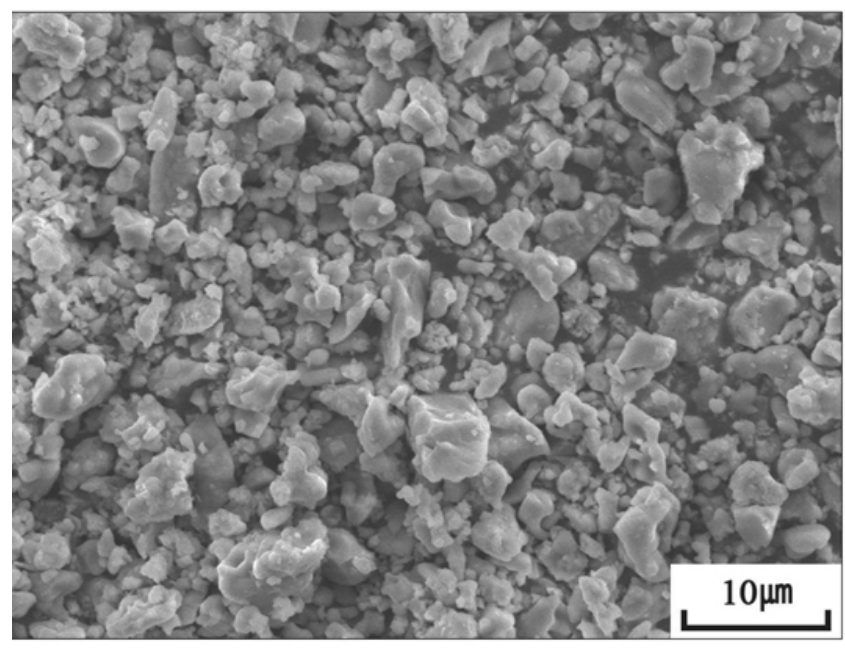

Figure 2. SEM image of HAP powder.

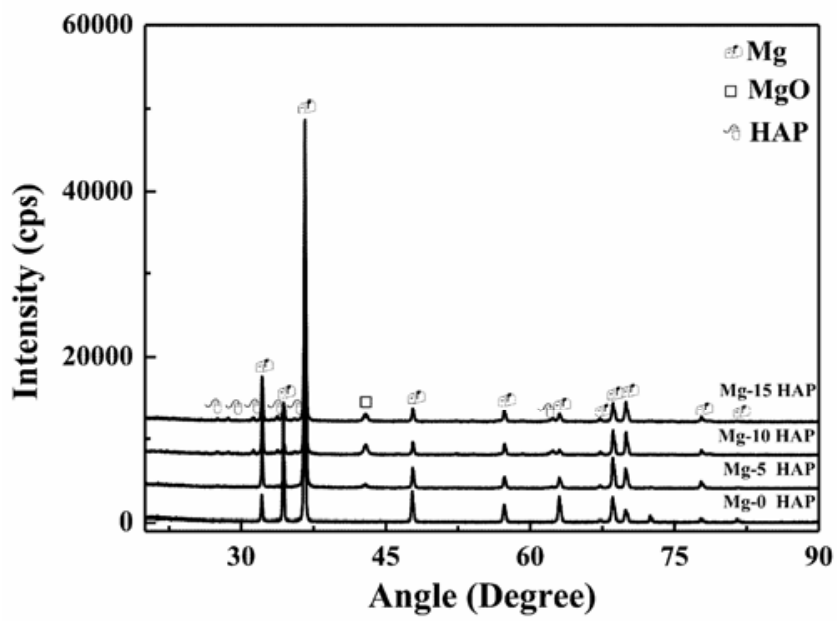

Figure 3. XRD patterns of $\mathrm{Mg}-\mathrm{HAP}$ composites.
$\mathrm{MgO}$ only in Mg-HAP composites indicates there is some interaction between $\mathrm{Mg}$ and HAP. It has also been observed that $\mathrm{MgO}$ is present in as-cast $\mathrm{Mg}-\mathrm{HAP}$ composites. This indicates that during melting process, $\mathrm{Mg}$ and HAP reacts to form $\mathrm{MgO}$. However, XRD pattern could not reveal presence of any other phases of apatite. Presence of adsorbed water in the HAP powders may be responsible as the source of water, which reacts with $\mathrm{Mg}$ during melting process. The optical images of $\mathrm{Mg}-\mathrm{HAP}$ composites are shown in figure 4. It shows presence of HAP particles (black) in the $\mathrm{Mg}$ matrix in case of $\mathrm{Mg}-10$ HAP. The microstructure of Mg-10 HAP mainly consists of agglomeration of HAP particles. The microstructure also reveals the decrease of grain size between $\mathrm{Mg}-0$ $\mathrm{HAP}$ and $\mathrm{Mg}-10 \mathrm{HAP}$. The relationship between grain sizes of $\mathrm{Mg}-\mathrm{HAP}$ composites is shown in figure 5 . The average grain size of $\mathrm{Mg}-0 \mathrm{HAP}$ is found to be $\sim 27 \mu \mathrm{m}$ and then it drastically decreases with the addition of HAP powder. This Mg-15 HAP contains average grain size of $\sim 13 \mu \mathrm{m}$ (figure 5). The presence of HAP particles in the $\mathrm{Mg}$ matrix during extrusion is responsible for grain refinement. The extrusion pressure is found to increase with the addition of HAP. The OM images with Vickers hardness indents of $\mathrm{Mg}-\mathrm{HAP}$ composites are shown in
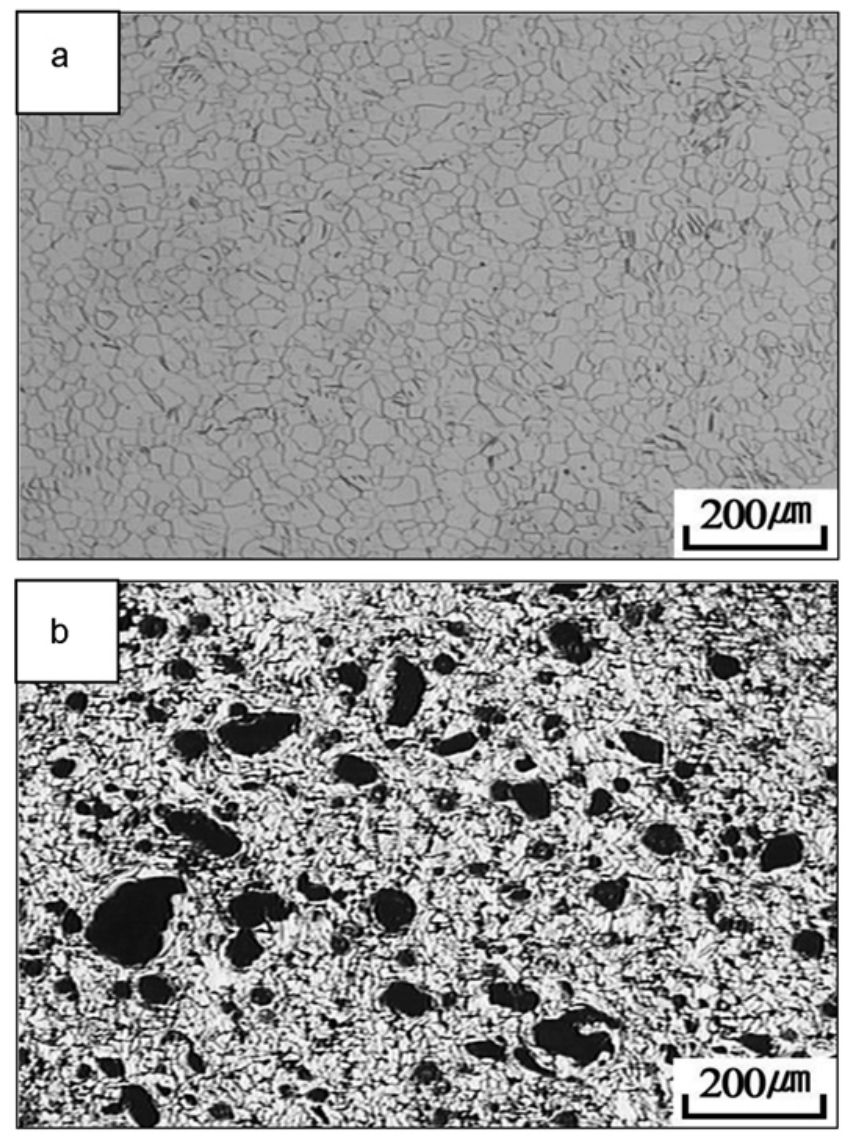

Figure 4. Microstructure of $\mathrm{Mg}-\mathrm{HAP}$ composites: a. $\mathrm{Mg}-0$ HAP and b. Mg-10 HAP. 
figure 6. It is quite difficult to get uniform distribution of agglomeration free HAP particles in the $\mathrm{Mg}$ matrix and it is also expected that the hardness of composites will vary with the nature of distribution of HAP particles. The indent shape in OM images indicates that it can make an average hardness of $\mathrm{Mg}-\mathrm{HAP}$ composites because the

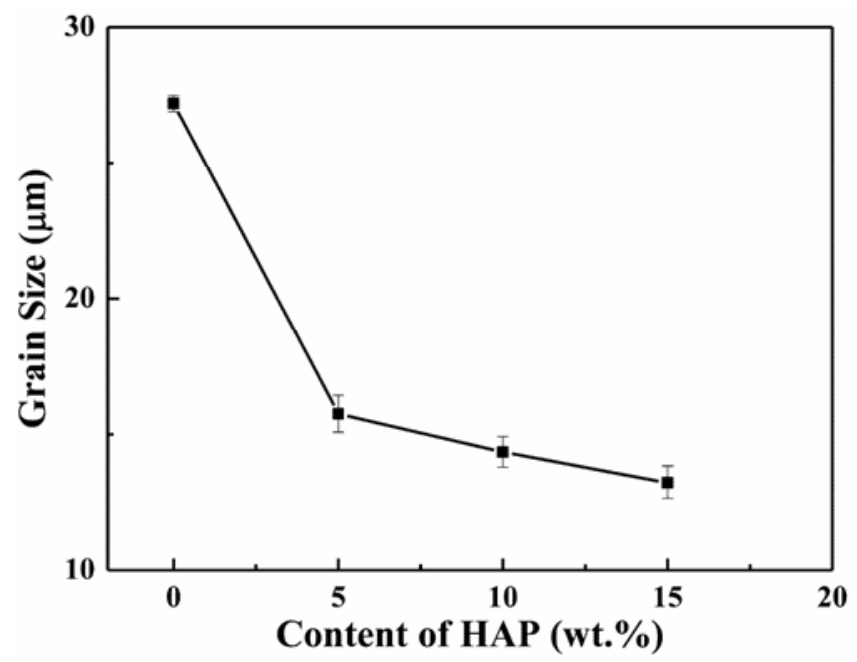

Figure 5. Grain size of $\mathrm{Mg}-\mathrm{HAP}$ composites.
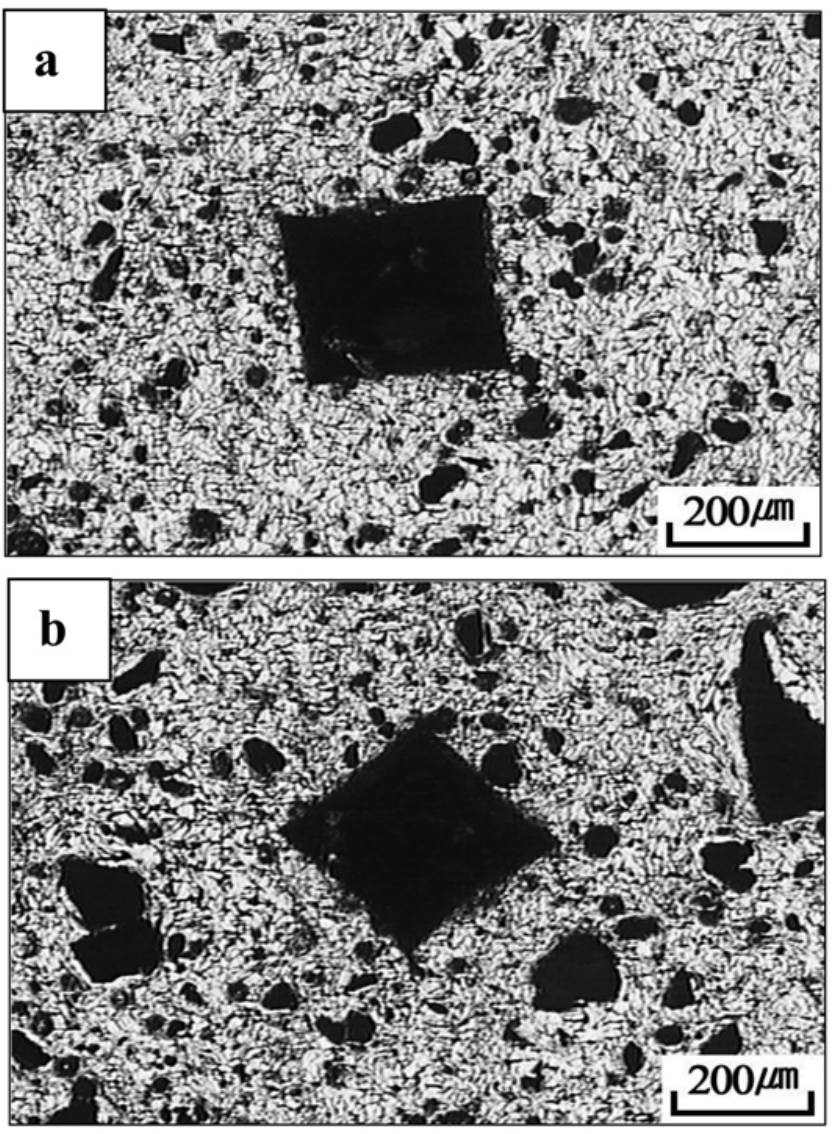

Figure 6. $\mathrm{OM}$ images with Vickers hardness indents of $\mathrm{Mg}-$ HAP composites: a. Mg-5 HAP and b. Mg-15 HAP. shape of indent is much bigger than agglomerate size of HAP. The average hardness plots of $\mathrm{Mg}-\mathrm{HAP}$ composites are shown in figure 7. The experimental hardness of composites is lower than the theoretical value. The hardness values are calculated from the volume fraction and hardness of individual $\mathrm{Mg}$ and HAP. The hardness of 99\% sintered HAP is used as reference hardness value for HAP (Paramanik et al 2007). Presence of different agglomerates sizes of HAP in the $\mathrm{Mg}$ matrix may result in decrease of hardness as compared to theoretical value. Witte et al have observed similar type of agglomeration problem in case of powder extruded AZ91-HAP composite (Witte et al 2007c). This indicates agglomeration problem cannot be overcome in both the melting and powder extrusion processes. The tensile strength of the Mg-HAP composites is found to decrease with the addition of HAP (table 1). A maximum tensile strength of $\sim 188 \mathrm{MPa}$ is observed for $\mathrm{Mg}-0 \mathrm{HAP}$, whereas $\mathrm{Mg}-15 \mathrm{HAP}$ shows minimum strength level of $\sim 137 \mathrm{MPa}$. The addition of hard phase (HAP) may result in decrease of tensile strength of composites. This indicates its brittleness increases with the HAP addition. There is no such trend in case of yield strength. It has also been observed that the elongation decreases with the HAP and this again is attributed to increase of brittleness behaviour of $\mathrm{Mg}-$

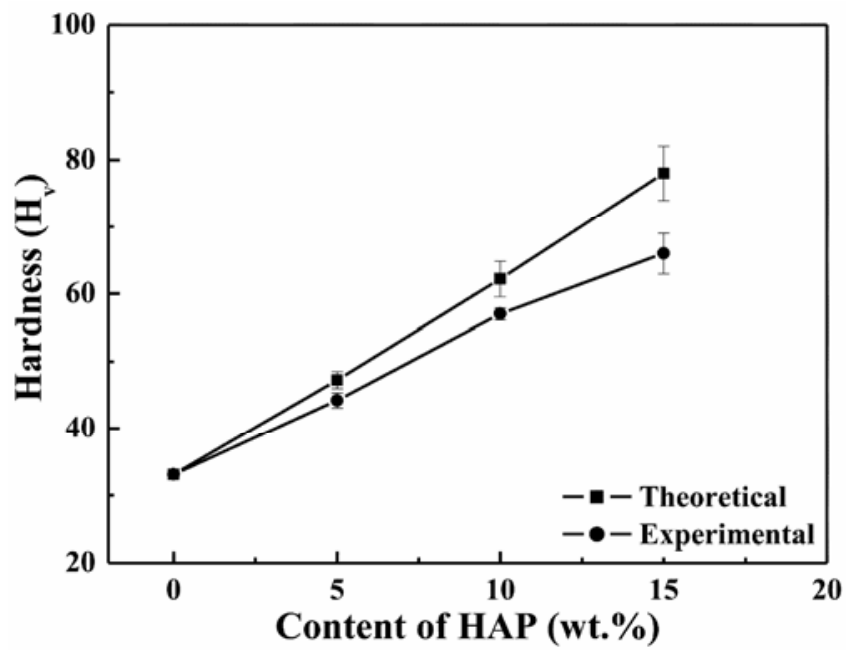

Figure 7. Relationship between theoretical and experimental hardness plots of Mg-HAP composites with HAP.

Table 1. Different properties of Mg-HAP composites measured during tensile strength.

\begin{tabular}{lccc}
\hline Composition & Sample name & $\begin{array}{c}\text { Yield } \\
\text { strength } \\
(\mathrm{MPa})\end{array}$ & $\begin{array}{c}\text { Tensile } \\
\text { strength } \\
(\mathrm{MPa})\end{array}$ \\
\hline 0 wt.\% HAP & $\mathrm{Mg}-0 \mathrm{HAP}$ & $124 \cdot 1$ & $187 \cdot 9$ \\
5 wt.\% HAP & $\mathrm{Mg}-5 \mathrm{HAP}$ & $122 \cdot 3$ & $171 \cdot 1$ \\
10 wt.\% HAP & $\mathrm{Mg}-10 \mathrm{HAP}$ & $137 \cdot 0$ & 146.4 \\
15 wt.\% HAP & $\mathrm{Mg}-15 \mathrm{HAP}$ & $129 \cdot 6$ & $136 \cdot 7$ \\
\hline
\end{tabular}




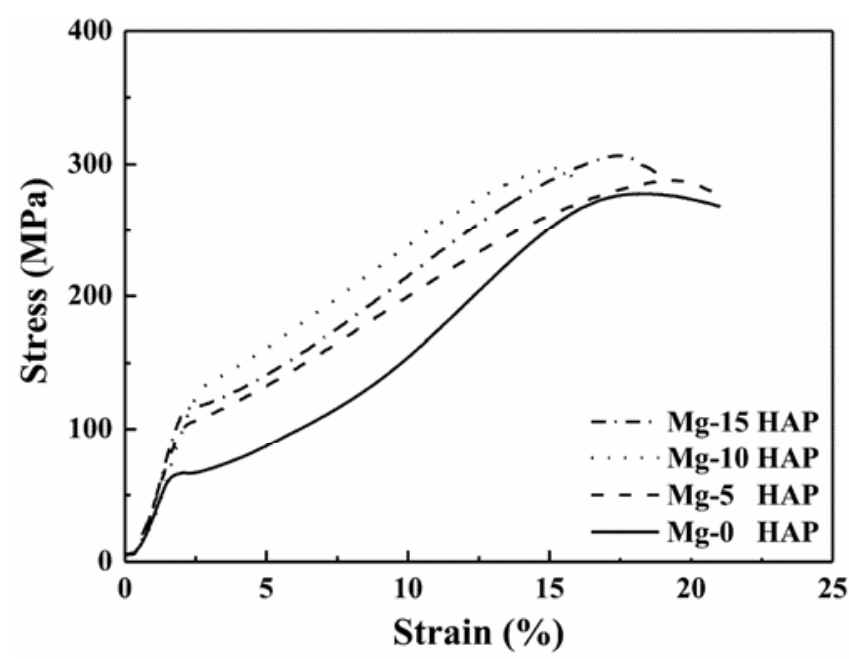

Figure 8. Compressive stress-strain curves of Mg-HAP composites.

HAP composites. The compressive stress-strain curves of $\mathrm{Mg}-\mathrm{HAP}$ composites are shown in figure 8 . The compressive strength of composite is found to increase with the addition of HAP. This phenomenon indicates increase of brittleness with HAP, which is in close agreement with the results of tensile strength behaviour of composites. The Mg-15 HAP and Mg-0 HAP composites show compressive strength of $\sim 305$ and $\sim 265 \mathrm{MPa}$, respectively.

\section{Conclusions}

To the best of our knowledge, we have for the first time produced biodegradable Mg-HAP composite by melting and extrusion route. The chemically synthesized HAP powders are used as reinforcing agent for Mg-HAP composites. The OM study reveals the relation between grain sizes with HAP. The hardness, tensile and compressive strength of $\mathrm{Mg}-\mathrm{HAP}$ composites are evaluated.

\section{Acknowledgements}

The research work was financially supported by MTIC, RIAM and BK21 Materials Education and Research Divi- sion. Authors would like to thank all members of MML, School of Materials Science and Engineering, Seoul National University, Seoul.

\section{References}

Chakraborty J, Sinha M K and Basu D 2007 J. Am. Ceram. Soc. 901258

Erbel R et al 2007 The Lancet 3691869

Kannan S, Ventura J M and Ferreira J M F 2007 Ceram. Int. 20 1397

Kannan S, Balamurugan A and Rajeswari S 2003 Mater. Lett. 572382

Kaya A A 2007 Int. Corr. Engg. Conf. Seoul 1256

Kwon S H, Jun Y K, Hong S H and Kim HE 2003 J. Euro. Ceram. Soc. 231039

Kim W and Saito F 2001 Ultason. Sonoche. 885

Mani G, Feldman M D, Patel D and Agrawal C M 2007 Biomater. 281689

Ning C Q and Zhou Y 2002 Biomater. 232909

Ormiston J and Webster M 2007 The Lancet 3691839

Paramanik S, Agarwal A K, Rai K N and Garg A 2007 Ceram. Int. 33419

Prakash H K, Kumar R, Ooi C P, Cheang P and Khor K A 2006 Langmuir 2211002

Ryu H S, Youn H J, Hong K S, Chang B S, Lee C K and Chung S S 2002 Biomater. 23909

Staiger M P, Pietak A M, Huadmai J and Dias G 2006 Biomater. 271728

Suchanek W L, Byrappa K, Shuk P, Riman R E, Janas V F and Tenhuisen K S 2004a Biomater. 254647

Suchanek W L, Byrappa K, Shuk P, Riman R E, Janas V F and Tenhuisen K S 2004b J. Solid State Chem. 177793

Thian E S, Loh N H, Khor K A and Tor S B 2002 Biomater. 23 2927

Witte F, Kaese V, Haferkamp H, Switzer E, Lindenberg A M, Wirth C J and Windhagen H 2005 Biomater. 263557

Witte F, Fischer J, Nellesen J, Crostack H A, Kaese V, Beckmann A P F and Windhagen H 2006 Biomater. 271013

Witte F, Ulrich H, Rudert $\mathrm{M}$ and Willbond E 2007a J. Biomed. Mater. Res. Part A $\mathbf{8 1} 748$

Witte F, Ulrich H, Palm C and Willbond E 2007b J. Biomed. Mater. Res. Part A 81757

Witte F, Feyerabend F, Maier P, Fischer J, Stromer M, Blawert C, Dietzel W and Hort N 2007c Biomater. 282163 